\title{
Experimental study on vegetation removing from irrigation channels
}

\author{
Yevgeniy Chayka ${ }^{1}$, Viktor Zhurba ${ }^{1,}$, , Natalia Krivtsova $^{1}$, Anna Khadzhidi $^{2}$, Pavel \\ Voshchevoz ${ }^{1}$, and Natia Ugrekhelidze ${ }^{1}$ \\ ${ }^{1}$ Don State Technical University, 1, Gagarin sq., 344003, Rostov-on-Don, Russia \\ ${ }^{2}$ Kuban State Agrarian University named after I.T. Trubilina, 13, Kalinina str, 350044, Russia
}

\begin{abstract}
The parameters of the process of vegetation removing from the water surface have been justified. An experiment was conducted to determine the strength of the screw-type tool and matching the most appropriate parameters. It was established that the channel clean-up quality depends on the screw diameter. It was also investigated the influence of the screw rotation speed on the channel clean-up quality. The dependence of the clean- up quality on the flight screw pitch has been determined.
\end{abstract}

\section{Introduction}

For cleaning irrigation and farm channels from vegetation and sediment, channel cleaners with active, high efficiency working elements are provided. However, the use of these machines does not completely solve the problem of removing weeds. Currently, the cleaning of the channels is carried out by mechanical methods, including mowing and removal of plant fragments from the channel.

Modern industry produces reclamation mowers with rotary and segmental working elements which provide a high-quality cut of vegetation, but the problem of removing cut vegetation remains relevant to the present time. Rotary- type tools can remove up to $65 \%$ of vegetation, segmental-finger tools do not cope with this task.[1-3]

Thus, when cleaning channels with the above-mentioned tools, the bulk of mown vegetation and other extraneous waste fills the channels, this significantly complicates the operation of hydraulic structures, pumping stations, and leads to their gradual or sudden failure.

According to data, up to 100 thousand tons of plant residues must be removed from irrigation channels every year. Existing tools for the removal of plant residues intended for installation at large pumping stations are complex, cumbersome, unreliable and have low technical and economic indicators. [4-5] Their usage in small pumping stations and culverts of the farm irrigation network is impractical. In addition, they are not adapted for waste intake from channels which are away from pumping stations grids. The literature does not provide recommendations for justifying the rational type of their tools, and there are no theoretical developments for matching the main parameters. This makes it difficult to create highly efficient tools for removing plant residues in open areas of irrigation channels.

${ }^{*}$ Corresponding author: vic.zhurba@yandex.ru 
Therefore, the purpose of this work is to find and study a tool designed to remove plant residues from water of farm irrigation channels.

\section{Materials and methods}

Screw-type tools are widely used in modern mechanical engineering. During their operation they have shown themselves as reliable, highly effective devices. The experience of their operation is very large but until recent time the screw-type tools have not been used for cleaning channels from plant residues, so when developing channels cleaners with similar working elements, there is not enough only theoretical justification for this technological process.

In order to match the most appropriate operating parameters and to visualize the process, it is necessary to conduct an experiment to determine the strength of the matched working element.

The experiment will allow us to check the working element under different conditions to find out the most suitable parameters for our working element for a specific channel [610]

The screw-type element of the plant residue cleaner has several parameters. To simplify the work we will distinguish three main ones: $T$ - the flight screw pitch cm, $D s$ - diameter of the screw cm, $n$ - speed, r.p.m.

Determine the output of the screw interaction process with plant stems in water by the indicator $Y, \%$

If three parameters are set to 3-4 experimental points, the total number of experiments in three replications will be:

$N=3 \cdot 4 \cdot 3=36$ experiments

When increasing to 5 experimental points, $N=45$ experiments.

To reduce the number of experiments and time we use experiment planning.

Let's take the following notation $X i-, X i+, X i O$ - respectively, the lower, upper and base levels $\Delta X i$ - the range of variation.

When planning an experiment the transformation of dimensional, controlled, independent factors $X$ into dimensionless ones is performed.[10-17].

Table 1. Coding factors and levels.

\begin{tabular}{|l|c|c|c|c|}
\hline \multirow{2}{*}{$\begin{array}{l}\text { Name of coding factors } \\
\text { and levels }\end{array}$} & physical & $\mathbf{T}, \mathbf{c m}$ & $\mathbf{D}, \mathbf{c m}$ & $\mathbf{n}, \mathbf{r p m}$ \\
\cline { 2 - 5 } & coding & $\mathrm{X}_{1}$ & $\mathrm{X}_{2}$ & $\mathrm{X}_{3}$ \\
\hline Upper level & +1 & 2 & 100 & 30 \\
\hline Neutral rating & 0 & 1.5 & 85 & 20 \\
\hline Down level & -1 & 1 & 70 & 10 \\
\hline Coding interval & 1 & 1 & 10 & 10 \\
\hline
\end{tabular}

\section{Results and discussion}

Using the theory of experiment planning you can build mathematical models that link the parameter under study with all the factors that affect it.

We suggest that in the complex system under consideration there is a functional relationship between the parameters of working elements or their models and the forces or moments acting. Then in general the mathematical description of the process is represented as a dependency.

$$
Y=f\left(X_{1}, X_{2}, X_{3}\right)
$$


where $Y$ is a dependent variable or response function (the parameter under study), $X 1, X 2, X 3$-independent variables that affect $Y$ (factors).[18-19]

This function can be represented as a regression equation for a three-factor experiment.

$$
Y=b_{0}+b_{1} X_{1}+b_{2} X_{2}+b_{3} X_{3}+b_{4} X_{1} X_{2}+b_{5} X_{1} X_{3}+b_{6} X_{2} X_{3}+b_{7} X_{1} X_{2} X
$$

where $Y$ is the response function values, $b_{0} b_{1} b_{2} b_{3} b_{4} b_{5} b_{6} b_{7}$ are the regression equation coefficients.

Estimates of $Y, b i$ are of practical value only when they are justifiable, effective, unbiased, and sufficient. This is provided if the following conditions are met: dependent variable values in each experiment, normally distributed random variables, an independent variable error and an dependent variable variance from experience to experience are homogeneous. [20]

Regression equation coefficients:

$$
b_{0}=\frac{\sum_{1}^{3} \sum_{1}^{8} Y_{i}}{8}
$$

where $b_{0}$ is the average process outcome in the experiment.

\begin{tabular}{|c|c|c|c|c|c|c|c|c|c|c|c|}
\hline \multirow{4}{*}{$\begin{array}{c}\text { № } \\
\text { experiment }\end{array}$} & \multirow{2}{*}{\multicolumn{3}{|c|}{$\begin{array}{l}\text { Factors } \\
\text { Natural }\end{array}$}} & \multirow{3}{*}{\multicolumn{4}{|c|}{ Works }} & \multirow{2}{*}{\multicolumn{4}{|c|}{ Experiments quality }} \\
\hline & & & & & & & & & & & \\
\hline & \multicolumn{3}{|c|}{ Coded } & & & & & \multicolumn{4}{|c|}{$Y_{\text {exp }}, \%$} \\
\hline & $X_{1}$ & $X_{2}$ & $X_{3}$ & $\begin{array}{l}X_{1} \\
X_{2}\end{array}$ & $\begin{array}{l}X_{1} \\
X_{3}\end{array}$ & $\begin{array}{l}X_{2} \\
X_{3}\end{array}$ & $\begin{array}{c}X_{1} X_{2} \\
X_{3}\end{array}$ & $Y_{1}$ & $Y_{2}$ & $Y_{3}$ & $\bar{Y}_{i}$ \\
\hline 1 & - & - & - & + & + & + & - & 63 & 59 & 57 & 59,6 \\
\hline 2 & + & - & - & - & - & + & + & 51 & 7 & 60 & 56 \\
\hline 3 & + & + & - & + & - & - & - & 73 & 69 & 64 & 68,6 \\
\hline 4 & + & + & + & + & + & + & + & 84 & 89 & 86 & 86,3 \\
\hline 5 & - & + & - & - & + & - & + & 79 & 81 & 84 & 81,3 \\
\hline 6 & - & - & + & + & - & - & + & 82 & 78 & 74 & 78 \\
\hline 7 & - & + & + & - & - & + & - & 93 & 88 & 89 & 90 \\
\hline 8 & + & - & + & - & + & - & - & 74 & 71 & 79 & 74,6 \\
\hline
\end{tabular}

Table 2. Plan matrix of three factors experiment.

$$
\begin{gathered}
b_{0}=74,3 \\
b_{i}=\sum_{1}^{8} x_{i b} \bar{Y}_{i}
\end{gathered}
$$

where $b_{i}$ - coefficients at factors.

$$
\begin{gathered}
b_{1}=\frac{-59,6+56+68,6+86,3-81,3-78-90,0+74,6}{8}=-2,93 \\
b_{2}=\frac{-59,6-56+68,6+86,3+81,3-78+90-74,6}{8}=7,25
\end{gathered}
$$




$$
\begin{aligned}
& b_{3}=\frac{-59,6-56-68,6+86,3-81,3+78+90+74,6}{8}=7,93 \\
& b_{4}=\frac{59,6-56+68,6+86,3-81,3+78-90-74,6}{8}=-1,18 \\
& b_{5}=\frac{59,6-56-68,6+86,3+81,3-78-90+74,6}{8}=1,15 \\
& b_{6}=\frac{59,6+56-68,6+86,3-81,3-78+90-74,6}{8}=-1,36 \\
& b_{7}=\frac{-59,6+56-68,6+86,3+81,3+78-90-74,6}{8}=1,1
\end{aligned}
$$

Let's put these coefficients in the regression equation:

$$
Y\left(x_{i}\right)=74,3-2,93 X_{1}+7,25 X_{2}+7,93 X_{3}-1,18 X_{1} X_{2}+1,15 X_{1} X_{3}-1,36 X_{2} X_{3}+1,1 X_{1} X_{2} X_{3}
$$

The hypothesis about the adequacy of the experimental results to the obtained regression equation is checked using F-test (Fisher test) in the following order:

- calculate the outcome $Y i$ for each experiment variant using the regression equation from which not significant (NS) terms are excluded

- find the difference $Y i-Y c$, where $Y c$ is the average value from replicate experiments

- calculate the adequacy variance

- calculate the Fisher test and compare the results with the table values.

If the calculated criterion is less than the tabular one for the corresponding degrees of freedom (d.o.f.)[21-24]

$$
f_{1}=L-d(4)
$$

where $d$ is the number of the approximation equation terms, $L-$ the number of fluctuations in the experiment.

$$
f_{2}=L(Z-1)
$$

where $Z$ is the number of replicate experiments.

When the value of $\mathrm{P}$ is set (usually $5 \%$ ), the control adequately describes the process.

$$
S_{t i l}^{2}=\frac{\sum\left(y_{i}-y_{c i}\right)^{2}}{N \cdot n}
$$

where $N$ is the number of experiments in the matrix, $n$ is the number experiment replications.

$$
\begin{gathered}
S_{t i l}^{2}=\frac{91,86+25,86+87,66}{8 \cdot 3}=\frac{205,38}{24}=8,56 \\
S_{a d}^{2}=\frac{\sum\left(y_{c i}-y_{T i}\right)}{N(n-1)}=\frac{0,0104}{8(3-1)}=65 \cdot 10^{-5}
\end{gathered}
$$




$$
F=\frac{S_{a d}^{2}}{S_{t i l}^{2}}=\frac{0,00065}{8,56}=76 \cdot 10^{-6}
$$

Table value of the Fisher test for $f 2=16$ and $f 1=1$ at $\mathrm{p}=0,05 F 1-\mathrm{p}=4,43$.

So, the equation adequately describes the process.[25-29]

For a more visual analysis of the experiment results we construct two-dimensional response variable.

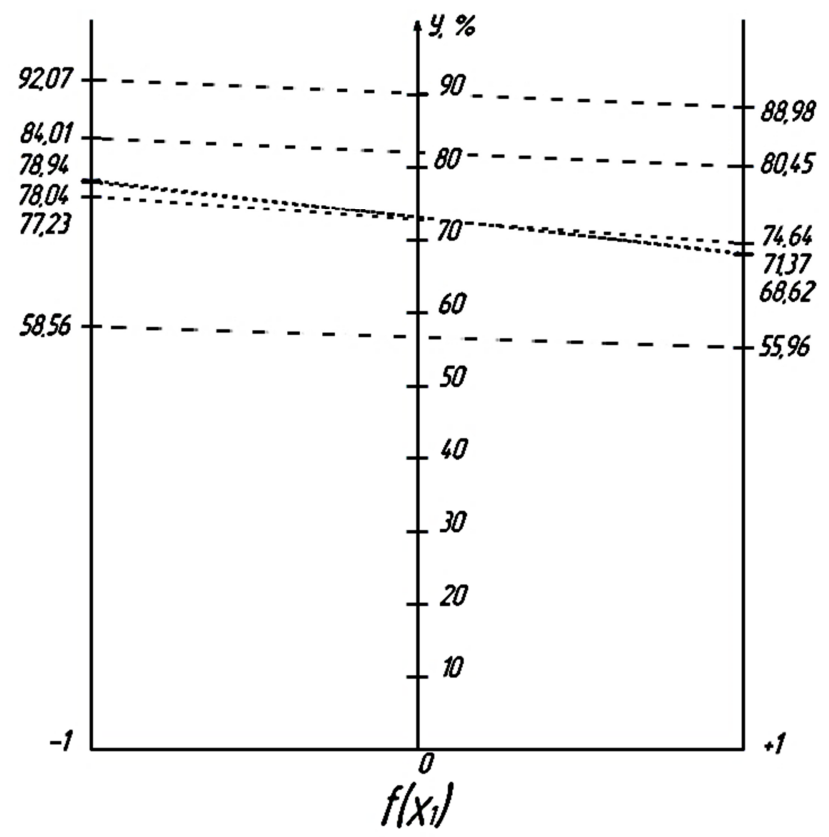

Fig. 1. Two-dimensional response section $Y=f(X 1)$.

$$
\begin{gathered}
X 2=0, X 3=0, Y=74,3-2,93 X 1 \\
X 2=1, X 3=1, Y=74,3-2,93 X 1+7,25+7,93-1,18 X 1+1,15 X 1+1,36+1,1 X 1=90,84-1,86 X 1 \\
X 2=-1, X 3=1, Y=74,3-2,93 X 1-7,25+7,93+1,18 X 1+1,15 X 1+1,36-1,1 X 1=76,34-1,7 X 1 \\
X 2=-1, X 3=1, Y=74,3-2,93 X 1-7,25-7,93+1,18 X 1-1,15 X 1-1,36+1,1 X 1=57,76-1,8 X 1 \\
X 2=1, X 3=-1, Y=74,3-2,93 X 1+7,25-7,93-1,18 X 1-1,15 X 1+1,36-1,1 X 1=73,8-5,18 X 1 ; \\
X 2=0, X 3=1, Y=74,3-2,93 X 1+7,93+1,15 X 1=82,23-1,78 X 1 .
\end{gathered}
$$






Fig. 2. Two-dimensional response section $Y=f(X 2)$.

$$
\begin{gathered}
X 1=0, X 3=0, Y=74,3+7,25 X 2 ; \\
X 1=1, X 3=0, Y=74,3+7,25 X 2-2,93-1,18 X 2=71,37+6,07 X 2 ; \\
X 1=0, X 3=1, Y=74,3+7,25 X 2+7,93-1,36 X 2=82,23+5,89 X 2 ; \\
X 1=-1, X 3=0, Y=74,3+2,93+7,25 X 2+1,18 X 2=77,23+8,43 X 2 ; \\
X 1=1, X 3=-1, Y=74,3-2,93+7,25 X 2-7,93-1,18 X 2-1,15-1,36 X 2-1,1 X 2=62,29+3,61 X 2 ; \\
X 1=-1, X 3=-1, Y=74,3+2,93+7,25 X 2-7,93+1,18 X 2+1,15-1,36 X 2+1,1 X 2=70,45+8,17 X 2 .
\end{gathered}
$$




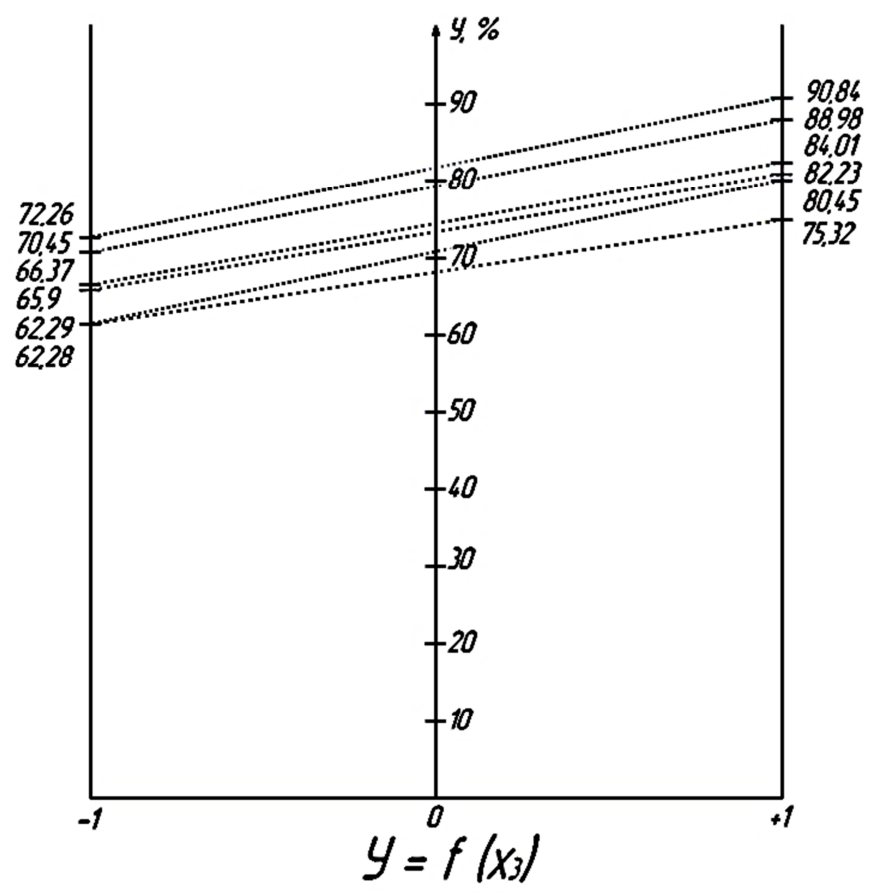

Fig. 3. Two-dimensional response section $Y=f(X 3)$.

$$
\begin{gathered}
X 1=0, X 2=0, Y=74,3-7,93 X 3 ; \\
X 1=1, X 2=0, Y=74,3-2,93+7,93 X 3+1,15 X 3=71,37+9,08 X 3 ; \\
X 1=0, X 2=1, Y=74,3+7,25+7,93 X 3+1,36 X 3=81,55+9,29 X 3 ; \\
X 1=-1, X 2=0, Y=74,3+2,93+7,93 X 3-1,15 X 3=77,23+6,78 X 3 ; \\
X 1=1, X 2=1, Y=74,3-2,93+7,25+7,93 X 3-1,18+1,15 X 3+1,36 X 3+1,1 X 3=77,44+11,54 X 3 ; \\
X 1=-1, X 2=-1, Y=74,3+2,93-7,25+7,93 X 3-1,18-1,15 X 3-1,36 X 3+1,1 X 3=68,8+6,52 X 3 .
\end{gathered}
$$

For the more visual consideration of the channel cleaning quality dependence on all three parameters $x i$, we construct a three-dimensional model of the response surface, (Figure 3).

Plane 1

$$
X 1=1, X 2=1, X 3=1
$$$$
Y=74,3-2,93+7,25+7,93-1,18+1,15-1,36+1,1=86,26 .
$$

$$
X 1=-1, X 2=1, X 3=1
$$

$Y=74,3+2,93+7,25+7,93+1,18-1,15-1,36-1,1=89,98$.

$$
X 1=-1, X 2=-1, X 3=1
$$




$$
\begin{gathered}
Y=74,3+2,93-7,25+7,93-1,18-, 1,15+1,36+1,1=78,04 . \\
X 1=1, X 2=-1, X 3=1 \\
Y=74,3-2,93-7,25+7,93+1,18+1,15+1,36-1,1=74,64 . \\
\text { Plane } 2 \\
X 1=1, X 2=1, X 3=-1 \\
Y=74,3-2,93+7,25-7,93-1,18-1,15+1,36-1,1=68,62 . \\
X 1=-1, X 2=1, X 3=-1 \\
Y=74,3+2,93+7,25-7,93+1,18+1,15+1,36+1,1=81,3.4 \\
X 1=-1, X 2=-1, X 3=-1 \\
X=74,3+2,93-7,25-7,93-1,18+1,15-1,36-1,1=59,56 . \\
X 1=1, X 2=-1, X 3=-1 \\
Y=74,3-2,93-7,25-7,93+1,18-1,15-1,36+1,1=55,96 .
\end{gathered}
$$

Plane 3

$$
\begin{gathered}
X 1=1, X 2=1, X 3=0 \\
Y=74,3-2,93+7,25-1,18=77,44 . \\
X 1=-1, X 2=1, X 3=0 \\
Y=74,3+2,93+7,25+1,18=85,66 . \\
X 1=-1, X 2=-1, X 3=0 \\
Y=74,3+2,93-7,25-1,18=68,8 . \\
X 1=1, X 2=-1, X 3=0 \\
Y=74,3-2,93-7,25+1,18=65,3 .
\end{gathered}
$$

\section{Discussion}

When designing the channel cleaner and conducting the experiment, the influence of almost all the main parameters of the tool was considered.

In particular, when changing the pitch angle of the horizontal screw rotation axis to the channel plane, an increase in productivity of the tool has been observed, since the operation of the screw is to move plant residues in the transverse direction to the inclined conveyor with the help of water pressure in the channel, which moving along the channel at the surface crashed into the tool and varying in magnitude and direction moves the vegetation floating on the surface along the channel. When the screw pitch increases, the base length 
of the entire machine also increases, which leads to an increase in its cost and the cost of its maintenance, i.e., the metal content of the machine and the power of the drive motor of the horizontal screw increases. Having a fairly long length of the machine we find these consequences unacceptable since even in the absence of the screw pitch angle to the channel cross section the tool corresponds to the required efficiency.[30-32]

When increasing the screw pitch angle to the water surface plane, we notice a deterioration in the tool operation, since when the flight surface interacts with the operating environment it interacts not only with vegetation floating but also with water amplifying the rotation resistant force. Moreover, this contributes to the setting of plant residues on the bottom which reduces the productivity of the tool. We accept the flight screw pitch angle $=$ $30^{\circ}$

With the change in the rotation frequency of the horizontal screw, there is a huge impact on its performance. With an increase in the number of rotations the productivity of the screw decreases, since the tool rotating at an increased speed interacts with water up to bubbling creating rotational water flows pushing aside vegetation before contact with the tool. Also, when the number of rotations increases, the screw drive power increases dramatically that is undesirable. In this regard, the design of the machine adopted a small speed of tool rotation $n=45 \mathrm{~min}-1$

One of the most important parameters of the screw is the flight pitch. This parameter affects many indicators of the efficiency of the technological process. It determines the speed of transportation and intake of plant residues from the channel. When the tool's flight increases, the quality of waste intake is improved, but the productivity weakens, since the number of rotations in the work decreases. When reducing the flight screw pitch, the quality of the long plant residues intake fells off, but the intake speed of small ones increases. When operating the screw, residues the length of which is longer than the flight pitch are thrown up directly to the tool rotation, the direction of which coincides with the direction of water flow. A floating fragment of vegetation is set from one or two edges and passing under the screw pipe crashes into a grid located parallel to the screw rotation axis. The grid and the tool interact so that the plant residue, regardless of size, is transported directly to the branch pipe to the column screw. However, this process is not often observed, as we would like, so when you install a channel cleaner in the area with prevailing plant residues it is recommended to fix small teeth along the flight screw length which would help to submerge large plant residues, herewith it would be well to change the direction of screw rotation and the design of the inclined conveyor.

When designing the machine, we take the horizontal screw rotation pitch $T=1000 \mathrm{~mm}$.

\section{Conclusions}

1. To remove plant residues from channels, moving grids made on the basis of chains are often used, which reduce the reliability of the mechanism. To eliminate these shortcomings, it is proposed to use a screw -type tool.

2. The results of experiments have allowed to determine the effect of the parameters of the tool on the quality of cleaning up the channel from vegetation. In particular, the number of tool rotations has the greatest impact.

3.The experimental data obtained will be used in the future when designing the machine, and they will also be taken into account when choosing the operating modes of the machine.[33-34] 


\section{References}

1. A. Errico, S. Francalanci, Preti, F. Chirico, Geosciences (Switzerland) 10(2), 47 (2020)

2. A. Khazipova, A. Chafizov, A. Komissarov, R. Mustafin, R. Zubairov, Asian Journal of Water, Environment and Pollution 17(1), 19-26 (2020)

3. N.A. Aleksikov, S.V. Artemova, Lecture Notes in Mechanical Engineeringc, 609-616 (2020)

4. L.E. Olgarenko, G.V. Ugryumova, A.A. Zamahovsky, M.P. Pautova, International Multidisciplinary Scientific GeoConference Surveying Geology and Mining Ecology Management, SGEM 19(3.1), 369-377 (2019)

5. V.I. Olgarenko, G. Olgarenko, V. Olgarenko, I. Olgarenko, IOP Conference Series: Earth and Environmental Science 337(1) (2019)

6. International Multidisciplinary Scientific GeoConference Surveying Geology and Mining Ecology Management, SGEM 18(3.1), 3-9 (2019)

7. E.A. Akhmedov, A.D. Borovoy, E.P. Khodiakov, IOP Conference Series: Earth and Environmental Science 341(1) (2019)

8. V.N. Shchedrin, A.A. Vasilyev, S.M. Kolganov, A.V. Medvedeva, L. Kupriyanov, Espacios 39(12), 28 (2018)

9. V.A. Podlipnov, V.V. Shchedrin, V.N. Babichev, A.N. Vasilyev, S.M. Blank, Computer Optics 42(5), 877-884 (2018)

10. Yu.M. Shchedrin, V.N. Kosichenko, Power Technology and Engineering 45(4), 264269 (2011)

11. R.S. Zhemukhov, M.M. Zhemukhova, IEEE Conference on Quality Management, Transport and Information Security, Information Technologies, IT and MQ and IS 7751942, 256-261 (2016)

12. M.M. Okonov, E.B. Dedova, Biosciences Biotechnology Research Asia 14, 2441-2449 (2015)

13. D.A. Solovyov, R.E Kuznetsov, D.G. Goryunov, S.V. Koshelev, N.I. Vavilova, Bulletin of the Saratov state agrarian University 5, 49-54 (2011)

14. V.I. Olgarenko, E. Olgarenko, N.S. Zakharchenko, O.P. Kisarov, Bulletin of the Russian Academy of agricultural Sciences 3, 34-36 (2011)

15. Yu.M. Kosichenko, M.Yu. Kosichenko, Yu.I. Iovchu, Technical science 3(161), 81-85 (2011)

16. Yu.A. Svistunov, A.Yu. Svistunov, Polythematic online electronic scientific journal of the Kuban state agrarian University 78, 413-423 (2012)

17. V.L. Snezhko, V.A. Kuchin, Branch aspects of technical Sciences 3(15), 24-27 (2012)

18. T.A. Pogorov, Scientific journal Of the Russian research Institute of land reclamation problems 2(10), 201-214 (2013)

19. A. Dominguez, C. Gómez, A.I. García-Kass, J.A. García-Nuñez, Lasers. Surg. Med. 42(1), 24-31 (2010) DOI: 10.1002/1sm.20873

20. M. Giannelli, L. Formigli, D. Lorenzini, L. Bani, J. Clin. Periodontol. 39(10), 962-970 (2012)

21. E.R. Kusek, A.J. Kusek, E.A. Kusek, Gen. Dent. 60(6), 54 (2012)

22. F. Sgolastra, M. Severino, R. Gatto, A. Monaco, Lasers. Med. Sci. 28(5), 1393-1402 (2013) DOI: $10.1007 / \mathrm{s} 10103$ 
23. A. Stabholz, Sh. Sahar-Helft, J. Moshonov, Alpha Omegan, 195-201 (2008) DOI: 10.1016/j.aodf.2008.07.029

24. A. Jamleh, H. Suda, C. Adorno, Dental Materials Journal, 1 - 5 (2017)

25. M.P. Arias, A.G. Maliza, R.Z. Midena, M.S. Graeff, M.H. Duarte, F.B. De Andrade, Appl. Oral. Sci. J. 24(6), 575 - 581 (2016)

26. L. Ch, Q. Zhong, Shanghai Kou Qiang Yi Xue, 314 - 316 (2017)

27. G. Plotino, T. Cortese, N.M. Grande, D.P. Leonardi, Brazilian Dental Journal 27(1), 38 (2016)

28. M. Middha, P. Sangwan, S. Tewar, J. Duhan, International Endodontic Journal 50, 522 -530 (2017)

29. P. Castelo-Baz, P. Varela-Patino, M. Ruiz-Pinon, F. Abella, R. Miquens-Vila, B. Martin-Biedma, J. Clin. Exp. Dent. 9(6), 789 - 793 (2017)

30. V. Zhurba, Y. Chayka, N. Gucheva, D. Ushakov, N. Ugrekhelidze, N. Kulikova, M. $\begin{array}{llllll}\text { Egyan, E3S Web of Conferences 135, } 01087 & \text { (2019) }\end{array}$ https://doi.org/10.1051/e3sconf/201913501087

31. V. Zhurba, N. Gordeeva, I. Mehantseva, A. Golubeva, Y. Kabanova, K. Shapovalenko, M. Davydova, E3S Web of Conferences 135, $01086 \quad$ (2019) https://doi.org/10.1051/e3sconf/201913501086

32. B. Meskhi, B. Golev, V. Efros, D. Rudoy, A. Olshevskaya, V. Zhurba, Y. Chayka, E3S Web of Conferences 135, 01083 (2019) https://doi.org/10.1051/e3sconf/201913501083

33. A. Altybayev, A. Zhanbyrbayev, B. Meskhi, D. Rudoy, A. Olshevskaya, A. Prohorova, E3S Web of Conferences 135, 01078 https://doi.org/10.1051/e3sconf/201913501078

34. G. Parkhomenko, S. Kambulov, A. Olshevskaya, A. Babadzhanyan, N. Gucheva, I. Mekhantseva, IOP Conf. Series: Earth and Environmental Science 403, 012144 (2019) doi:10.1088/1755-1315/403/1/012144 